\title{
An Equilibrium Model of Macro Financial Risk Alert and Measurement
}

\section{Huizhen Long \\ University of Wisconsin-Milwaukee ,53211}

\begin{abstract}
An equilibrium model of macro-financial system is crucial to the stability of the wholly country and society, and an effective financial risk alert system is important for macro-economic policy formulation as it can detect and predict financial crisis. This paper designs an integrated equilibrium model through three aspects: choosing risk alert indicators on previous literatures, judging financial risk ranks by factor analysis and history data, applying BP neural network to design an equilibrium model and form an prediction of financial crisis in 2010, and the predication shows that the total macro-financial is running safely, but there are some insecure facts which still exist in the macro-economic sub-system and external financial sub-system. The research in this paper is very significant to our country and can provide certain reference for the investigation in the future.
\end{abstract}

Keywords: Equilibrium Model, Macro Financial Risk, Alert, Measurement

\section{Introduction}

With the rapid development and the deepening, the financial system has become a core part of the macroeconomic constraints. Not only the degree of financial development restrict economic development, the volatility of the financial system indeed affects the whole body, and quickly spread to overall economic. Thus, measurements should be taken to avoid the macro financial risk and establish the alert system. The assumption of no arbitrage is central to an enormous finance literature that is devoted to the empirical analysis of bond pricing and the yield curve. The finance and macroeconomic research literatures have developed, to a remarkable extent, in isolation of each other, despite sharing many objects of keen mutual interest, notably, the short-term interest rate. From a finance perspective, the short rate is a fundamental building block for rates of other maturities because long yields are risk-adjusted averages of expected future short rates. From a macro perspective, the short rate is a key policy instrument under the direct control of the central bank, which adjusts the rate in order to achieve the economic stabilization goals of monetary policy.

This paper provides an example of a model that takes such a joint perspective, which we find yields interesting synergetic results. For example, in our combined macro-finance analysis, we find that the standard no-arbitrage term structure factors do have clear macroeconomic underpinnings. Therefore, an explicit macro structure can help to provide insight into the behavior of the yield curve beyond what a pure finance model can suggest.

The early alert system design of financial risk includes three aspects: the scope of the system, the crisis of the meaning and application of the model. This paper studies the financial operation of China from 1998 to 2009, and extract the three levels and 16 targets of financial risk of alert system in accordance with domestic and international financial crisis on the results of the study, and then combined with principal component analysis and BP neural network model, the paper establishes a macro financial risk alert system to achieve forecast and measurements are taken to compose an equilibrium model. 


\section{Theory of Financial Risk and Early Warning System}

The international research on financial risk early alert system is divided into two major parts, the first part of the financial crisis and the associated research of risks, including the definition and other causes of the crisis, and the second part is the study of the financial crisis alert model.

In the study of the financial crisis, the main study includes the BOP commodity price stabilization mechanism on the basis of the currency crisis model, which considers the exchange rate fluctuations which leads to the deterioration of macroeconomic fundamentals and the increase is caused by the root of the crisis, and the proposer believed that in the country's financial crisis, macroeconomic policy and exchange rate policies often conflict essentially. Obstfeld established a second-generation crisis theory on basis of self-realization and the theory means that the crisis occurrence is related to the government's actions. As a pursuit of optimal economic man, the government maintain a fixed exchange rate of earnings by balancing to decide whether to abandon the fixed exchange rate system. At the same time, the theory also believe that the behavior of the government and the private sector is not linear, and therefore will lead to multiple equilibria. Then, there are several possibilities in economic fundamentals operational status and financial crisis, even in the economic fundamentals of running. Under favorable circumstances, may the theory be used to explain the European currency crisis and the Mexican peso crisis? Krugman proposed a model of the fourth generation of the financial crisis, the focus of the model is concerned that a currency crisis. It is clear that the relationship between the domestic asset prices and currency crisis, emphasizing the confidence effects of domestic asset prices can lead to self-fulfilling pessimism by subject triggered by the financial crisis and the collapse of investment, such as Japan's bubble economy burst.

In the study of financial alert models, including FR model, which is probability regression models constructed according to the data of 105 developing countries from 1971-1992 years. FR model means that the factors causing the financial crisis are multiple and independent of each other. By calculating the joint probability of these factors, we can know the probability of crises. In addition, there is STV model, which is the cross-sectional regression model based on panel data. Compared with FR model, this model can reflect the contagion effects in different countries, but cannot predict the timing of crises. The third model is the KLR model which is currently the most important predictive model with non-parametric analysis, it is first to identify early alert indicators which have been studied by reason of currency crises. Then, through statistical analysis of historical data, we can find a significant leading indicator. Based on these indicators, we can predict the likelihood of crises. In addition to the three classical models, with the development of artificial intelligence, artificial neural network can be developed into a new financial crisis alert model.

Domestic scholars on the financial risk alert system focus on two aspects: the first is financial risk alert system indicators choice, and the second is the domestic financial alert system and empirical research of different research model. 


\section{Index Selection of Equilibrium Model of Macro Financial Risk Alert System}

Financial risk alert system is to determine the framework of the basic elements of early warning indicators. In the study of currency crises in the application of the four-level indicators: recurring items index - the real exchange rate, imports and exports; capital indicators - foreign exchange reserves and other reserves accounted $\mathrm{M} 2$ ratio; real economic indicators - Industrial GDP growth; financial indicators --M2 money multiplier, domestic credit / GDP, interest rate / deposit interest rates.

Meanwhile, each index of four run trend determines the critical value, which can be seen in Table1.

Tab. 1 China's macro-financial critical value of alert system

\begin{tabular}{l|l|l|l|l}
\hline Index & Safety & Potentially unsafe & Apparent insecurity & Crisis \\
\hline X1 & $8-12$ & $6.5-8$ & $4-6.5$ or $>12$ & $<4$ \\
\hline X2 & $<3$ & $3-5$ & $5-7$ & $>7$ \\
\hline X3 & $<7$ & $7-9$ & $9-12$ & $>12$ \\
\hline X4 & $1.5-5$ & $(-0.5)-1.5$ or $5-8$ & $-2-(-0.5)$ or $8-10$ & $<-2$ or $>10$ \\
\hline X5 & $13-20$ & $9-13$ or $20-25$ & $5-9$ or $25-30$ & $<5$ or $>30$ \\
\hline X6 & $8-18$ & $5-8$ or $18-23$ & $3-5$ or $23-27$ & $<3$ or $>27$ \\
\hline X7 & $60-120$ & $50-60$ or $120-150$ & $40-50$ or $150-200$ & $<40$ or $>200$ \\
\hline X8 & $<165$ & $165-200$ & $200-250$ & $>250$ \\
\hline X9 & $1-4$ & $<1$ or $4-6$ & $6-10$ & $>10$ \\
\hline X10 & $150-250$ & $100-150$ or $250-300$ & $50-150$ or $300-350$ & $<50$ or $>350$ \\
\hline X11 & $20-40$ & $<20$ or $40-55$ & $55-70$ & $>70$ \\
\hline X12 & $30-50$ & $<30$ or $50-100$ & $100-150$ & $>150$ \\
\hline X13 & $<10$ & $10-20$ & $20-30$ & $>30$ \\
\hline X14 & $<3$ & $3-8$ & $8-13$ & $>13$ \\
\hline X15 & $15-30$ & $10-15$ or $30-40$ & $3-10$ or $>40$ & $<3$ \\
\hline X16 & $20-40$ & $10-20$ or $40-50$ & $3-10$ or $50-70$ & $<3$ or $>70$ \\
\hline
\end{tabular}

In order to make a more effectively neural network analysis, principal component analysis can be used to reduce the number of variables. This is because that for the neural network, with excessive input variables, the network structure becomes complicated, the training load on the network increases, and learning speed declines sharply. While too many variables are not conducive to control warning system, and reduce the effectiveness of alert systems. The BP neural network model can be seen in Fig.1.

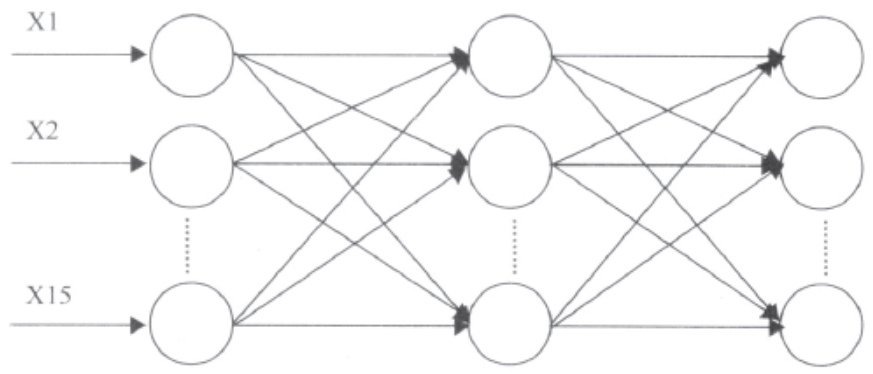

Fig.1 BP neural network model 


\section{Conclusions}

The conclusions can be seen as follows: First, according to the research on the financial crisis, the development of a suitable system of alert indicators of our country consists of three levels and16 indicators, respectively. Second, based on historical data and related research, the paper put it that our financial system is divided into four parts, namely, security, unsafe potentially, insecure and emerged crisis. Analysis of alert indicators is conducted using data from 1998 to 2009. Third, the application of principal component analysis divides the 16 alert indicators into three main components, namely, macroeconomic subsystem, financial subsystem and external financial subsystem.

To improve the effectiveness of our financial alert mechanism, some measurements are proposed. First, we must establish a sound financial information system, the formation of real-time and accurate economic and financial information sharing system. Only by making sharing information unimpeded, can we get timely and accurate access to the current value of the indicators affecting the operation of the financial system, which is an effective alert system to establish financial premise. Secondly, we must design a scientific and effective alert system, which includes the establishment of the different regional and temporal scope of the alert mechanism, and the establishment of different domain of the long-term, short-term, annual and quarterly alert mechanism. From the scope of the crisis, it must establish a currency crisis, capital market crisis, macro-financial crisis from different levels of the alert system.

\section{References}

[1] Andrew Berg, Catherine Pattillo. Predicting currency crises: The indicators approach and an alternative[J]. Journal of International Money and Finance, 1999, (18).

[2] Liu C, Wang F. In-orbit estimation of inertia parameters of target satellite after capturing the tracking satellite[C]//Intelligent Control and Automation (WCICA), 2014 11th World Congress on. IEEE, 2014: 3940-3945.

[3] Krugman, Paul. Crises: The Next Generation[R]. March 2001.

[4] Kaminsky, G.L., S.Lizondo and C.M.Reinhart. Leading Indicators of Currency rises[R]. IMF Staff Paper, 1998, Vol.45, No.1.

[5] Liu C, et al. Robust $\mathrm{H} \infty$ Control for Satellite Attitude Control System with Uncertainties and Additive Perturbation[J]. International Journal of Science, 2014, 1(2): 1-9.

[6] Shi K, Sun Z, Liu C. Design of Microsatellite Attitude Control with Multiplicative Perturbation of Controller[C]//Control and Decision Conference (2015 CCDC), The 27th Chinese. IEEE, 2015.

[7] Frankel, J.A.and A.K.Rose.Currency Crashes in Emerging Markets: An Empirical Treatment[J]. Journal of International Economics, 1996, (41).

[8] Rudebusch G D, Wu T. A Macro - Finance Model of the Term Structure, Monetary Policy and the Economy*[J]. The Economic Journal, 2008, 118(530): 906-926.

[9] Hali J. Edison. Do Indicators of Fnancial Crises Work? An Evaluation of an Early Warning System[R].

http://www.federalreserve.gov/pubs.htm, 2000, (7). 